\title{
Single Point Incremental Forming of AA1050-H18 Alloy Frustum of Cone Cups
}

\author{
V. Srija ${ }^{1}$, A. Chennakesava Reddy ${ }^{2}$ \\ ${ }^{1}$ PG student Department of Mechanical Engineering, JNTUH College of Engineering, Kukatpally, Hyderabad - 500 085, Telangana, India \\ ${ }^{2}$ Professor, Department of Mechanical Engineering, JNTUH College of Engineering, Kukatpally, Hyderabad - 500 085, Telangana, India
}

\begin{abstract}
The purpose of the present project work was to understand the formability of AA1050-H18 alloy to fabricate frustum of cone cups using single point incremental forming (SPIF) process. The finite element analysis has been carried out to model the single point incremental forming process using ABAQUS software code. The process parameters of SPIF were sheet thickness, step depth, tool radius and coefficient of friction. The process parameters have been optimized using Taguchi techniques. The major process parameters influencing the SPIF of truncated pyramidal cups were tool radius and sheet thickness.
\end{abstract}

Keywords: AA1050-H18 alloy, cone cup, single point incremental forming, finite element analysis, step depth, tool radius, sheet thickness, coefficient of friction.

\section{Introduction}

Deep drawing is a sheet metal forming process in which a sheet metal blank is radially drawn into a forming die by the mechanical action of a punch (figure 1). In a series of research on deep drawing process to fabricate variety of cup shapes (figure 2), rich investigation have been carried out to improve the superplastic properties of materials such as AA1050 alloy [1], AA1070 alloy [2], AA1080 alloy [3], AA1100 alloy [4], AA2014 alloy [5], AA2017 alloy [6], AA2024 alloy [7], AA2219 alloy [8], AA2618 alloy [9], AA3003 alloy [10], AA5052 alloy [11], AA5039 alloy [12], Ti-Al-4V alloy [13], EDD steel [14], gas cylinder steel [15]. The different cup shapes such as pyramidal $[2,16]$, rectangular $[3,17]$ and cone $[4,18]$ were fabricated.

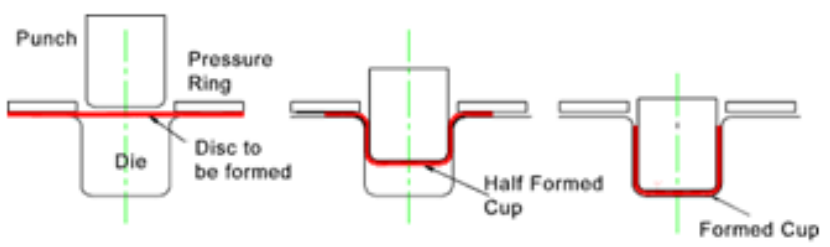

Figure 1: Conventional deep drawing process

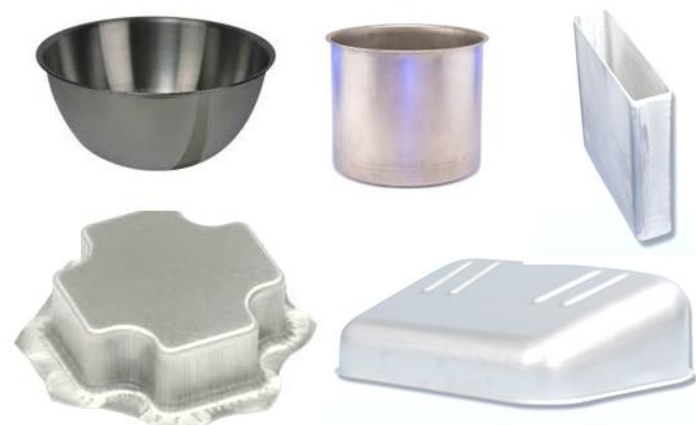

Figure 2: Different shapes fabricated by conventional deep drawing process

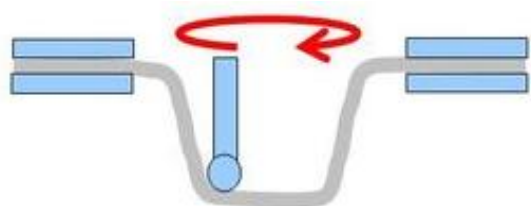

Figure 3: Single point incremental deep drawing process

Incremental sheet forming (SPIF) process has been identified as a potential and economically viable process for sheet metal prototypes and low volume production. In SPIF process (figure 3), the sheet material is clamped along its edges and a hemispherical headed tool is moved along a predefined geometrical path so that it deforms the sheet locally along the path. In this process, the forming die is not used. The process is very flexible and can be carried out on a computer numerical control (CNC) milling machine. The effect of step depth, feed rate and diameter of the tool on maximum wall angle were studied in cold incremental sheet forming of titanium sheet [19]. In another research, the frustum of cone and pyramid with different slope angles from a sheet of $100 \mathrm{~mm} \times$ $100 \mathrm{~mm}$ size. The cone had been formed with top base diameter $70 \mathrm{~mm}$ and depth $39 \mathrm{~mm}$, and pyramid had been formed with top side length of $100 \mathrm{~mm}$ and maximum depth of $35 \mathrm{~mm}$. The numerical simulations were also performed using LS-DYNA to analyze the formability [20].

The current study was to evaluate the formability of frustum of cone cups of AA1050 alloy using SPIF by finite element method. For this purpose the design of experiments was executed as per Taguchi technique. The process parameters of SPIF were sheet thickness, step depth, tool radius and coefficient of friction.

\section{Finite Element Modeling}

The finite element modeling of SPIF process was carried out using ABAQUS (6.14) software code to fabricate frustum of cone cups. The material was AA1050 alloy. The SPIF process parameters were chosen at three levels as summarized in Table 1. The orthogonal array (OA), L9 was pre- 


\section{International Journal of Science and Research (IJSR) \\ ISSN (Online): 2319-7064}

Index Copernicus Value (2013): 6.14 | Impact Factor (2015): 6.391

ferred to carry out experimental and finite element analysis (FEA) as given in Table 2.

Table 1: Process parameters and levels

\begin{tabular}{|l|l|l|l|l|}
\hline Factor & Symbol & Level-1 & Level-2 & Level-3 \\
\hline Sheet thickness, mm & A & 1.0 & 1.2 & 1.5 \\
\hline Step depth, mm & B & 0.50 & 0.75 & 1.00 \\
\hline Tool radius, mm & C & 4.0 & 5.0 & 6.0 \\
\hline Coefficient of friction & D & 0.05 & 0.10 & 0.15 \\
\hline
\end{tabular}

Table 2: Orthogonal Array (L9) and control parameters

\begin{tabular}{|c|c|c|c|c|}
\hline Treat No. & $A$ & $B$ & $C$ & $D$ \\
\hline 1 & 1 & 1 & 1 & 1 \\
\hline 2 & 1 & 2 & 2 & 2 \\
\hline 3 & 1 & 3 & 3 & 3 \\
\hline 4 & 2 & 1 & 2 & 3 \\
\hline 5 & 2 & 2 & 3 & 1 \\
\hline 6 & 2 & 3 & 1 & 2 \\
\hline 7 & 3 & 1 & 3 & 2 \\
\hline 8 & 3 & 2 & 1 & 3 \\
\hline 9 & 3 & 3 & 2 & 1 \\
\hline
\end{tabular}

The sheet and tool geometry were modeled as deformable and analytical rigid bodies, respectively, using ABAQUS. They were assembled as frictional contact bodies. The sheet material was meshed with S4R shell elements (figure 4a). The fixed boundary conditions were given to all four edges of the sheet. as shown in figure $4 \mathrm{~b}$. The boundary conditions for tool were $\mathrm{x}, \mathrm{y}, \mathrm{z}$ linear movements and rotation about the axis of tool [21]. True stress-true strain experimental data were loaded in the tabular form as material properties. The tool path geometry was generated using CAM software [22] was imported to the ABAQUS as shown in figure 5. The formability analysis was carried out for the equivalent stress, strain and strain rates and thickness reduction.
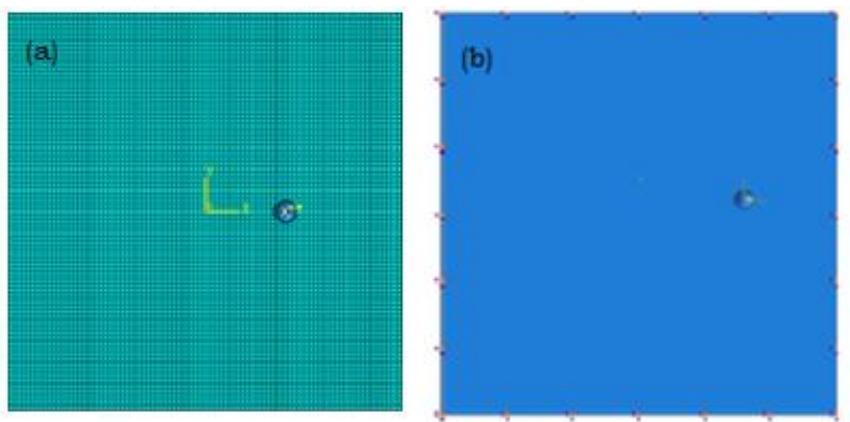

Figure 4: Finite element modeling: (a) mesh generation and (b) boundary conditions.

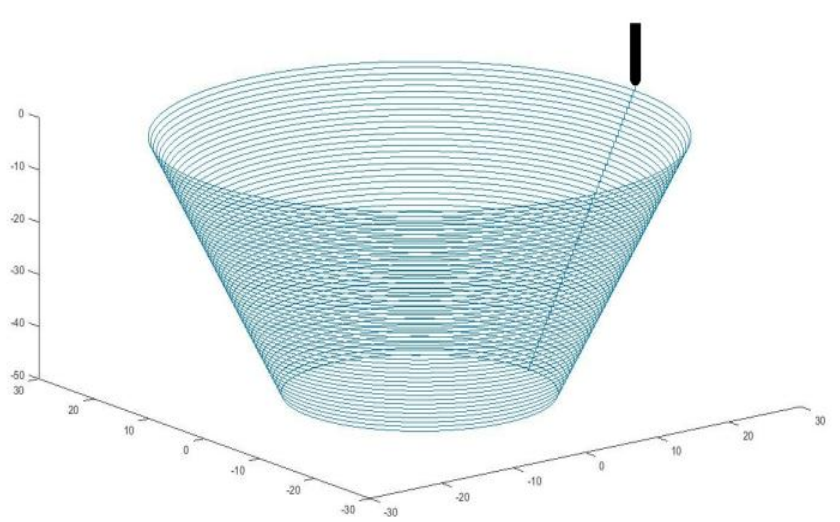

Figure 5: Tool path generation.

\section{Results and Discussion}

The Fisher's test was confirmed to accept all the parameters (A, B, C and D) at $90 \%$ confidence level. Hence, the process parameters which had an absolute Fisher's ratio larger than 3.4579 were believed to influence the average value for the forming characteristic under null hypothesis, parameters which had Fisher's ratio less than 3.457 were believed to have no effect on the average.

\subsection{Influence of process parameters on effective stress}

Table -3 gives the ANOVA (analysis of variation) summary of effective stress data. Towards total variation on the effective stress, the influence of coefficient of friction (D), step depth (B), sheet thickness (A) and tool radius (C) in the descending order are, respectively, $52.02 \%, 16.39 \%, 16.01 \%$ and $15.51 \%$.

Table 3: ANOVA summary of the effective stress

\begin{tabular}{|c|c|c|c|c|c|c|c|c|}
\hline Source & Sum 1 & Sum 2 & Sum 3 & $S S$ & $v$ & $V$ & $F$ & $P$ \\
\hline A & 504 & 499.7 & 496.7 & 8.965 & 1 & 8.97 & 1794.00 & 16.01 \\
\hline B & 499.8 & 496.6 & 504 & 9.175 & 1 & 9.18 & 1836.00 & 16.39 \\
\hline C & 496.7 & 499.8 & 503.9 & 8.685 & 1 & 8.69 & 1738.00 & 15.51 \\
\hline D & 503.9 & 504 & 492.5 & 29.125 & 1 & 29.13 & 5825.99 & 52.02 \\
\hline E & & & & 0.02 & 4 & 0.005 & 1.00000 & 0 \\
\hline T & 2004.4 & 2000.1 & 1997.1 & 55.97 & 8 & & & 100 \\
\hline
\end{tabular}

Note: $\mathrm{SS}$ is the sum of square, $\mathrm{v}$ is the degrees of freedom, $\mathrm{V}$ is the variance, $\mathrm{F}$ is the Fisher's ratio, $\mathrm{P}$ is the percentage of contribution and $\mathrm{T}$ is the sum squares due to total variation.
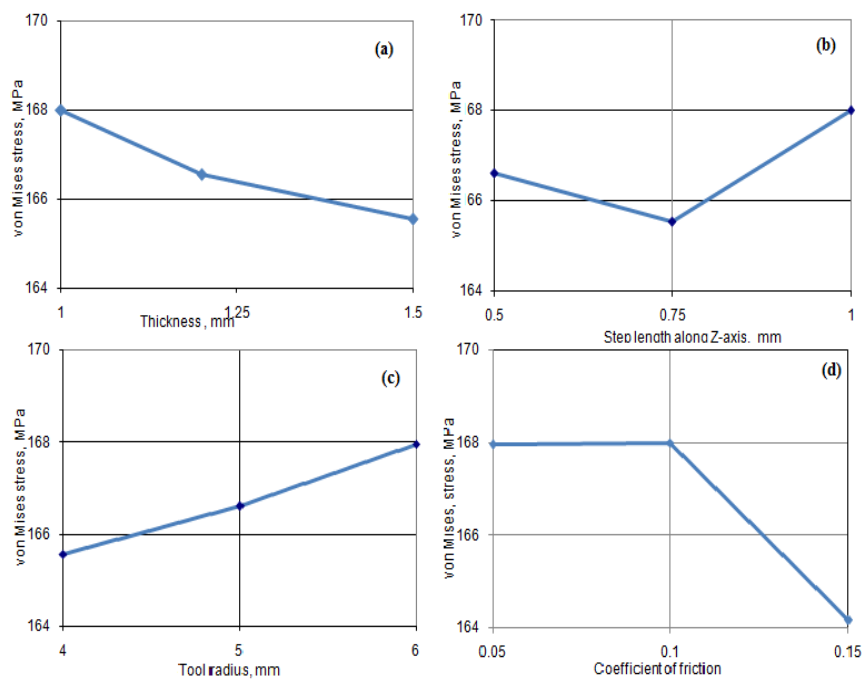

Figure 6: Influence of process parameters on von Mises stress.

The influence of SPIF process parameters on von Mises stress is shown in figure 6 . As seen from figure $4 a$, the increase of sheet thickness decreased the von Mises stress. As stress is force /area, the stress induced decreases with increase in the area of cross-section, The area of cross-section depends on the sheet thickness. The effective stress was very low for the step size of $0.75 \mathrm{~mm}$ as seen in figure $4 \mathrm{~b}$. Figure $4 \mathrm{c}$ expresses the effective stress as a function of tool radius. The effective is directly proportional to the tool radius. This 


\section{International Journal of Science and Research (IJSR) \\ ISSN (Online): 2319-7064 \\ Index Copernicus Value (2013): 6.14 | Impact Factor (2015): 6.391}

is due to the increase in area of sheet under the tool. The variation of coefficient of friction from 0.05 to 0.1 did not influence the effective stress; but, further increase in coefficient of friction decreases the effective stress. The principal stresses $S_{11}, S_{22}$ and shear stress $S_{12}$ are shown in figures 7,8 and 9 respectively. The principle stress $S_{11}$ and $S_{22}$ are highly compressive up to the plastic strain 2; while the shear stress $\mathrm{S}_{12}$ is due to tension in the sheet.

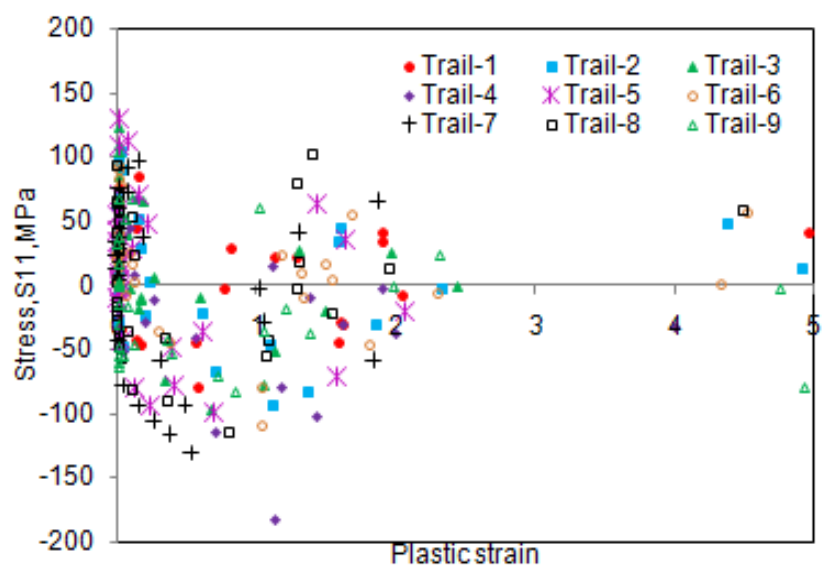

Figure 7: Effect of process parameters on $\mathrm{S}_{11}$.

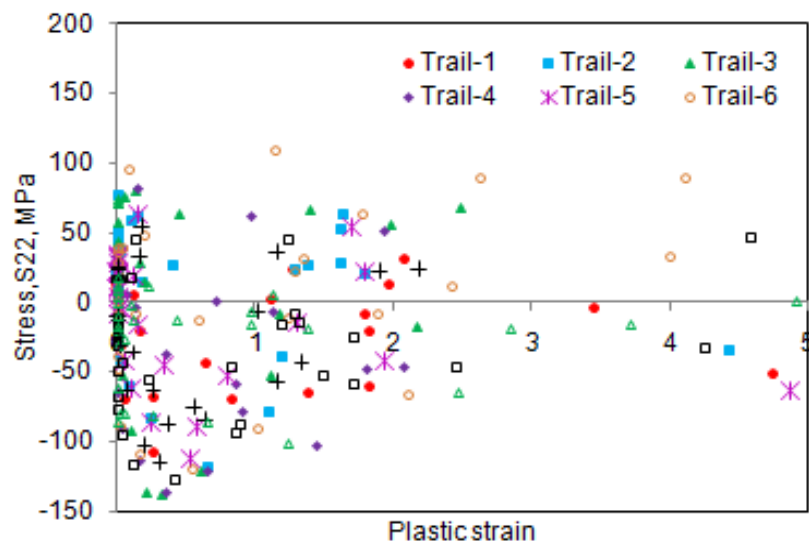

Figure 8: Effect of process parameters on $S_{22}$.

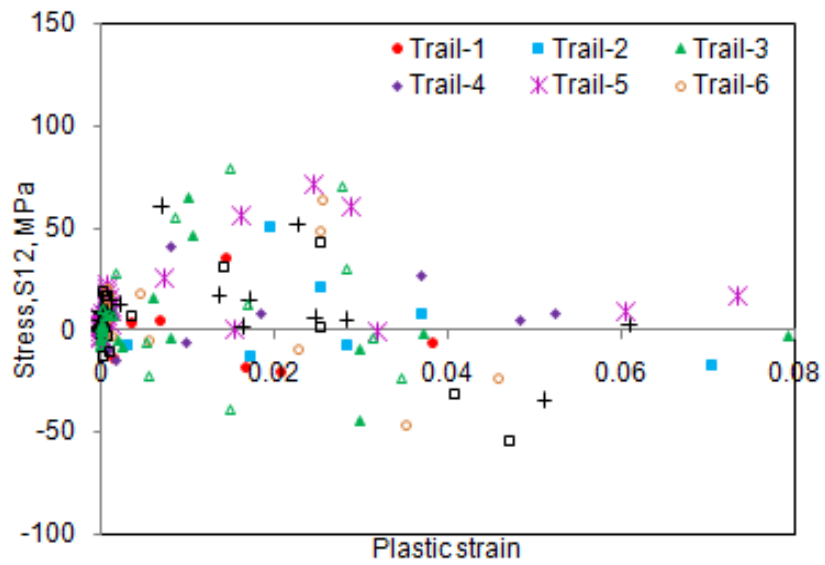

Figure 9: Effect of process parameters on $S_{12}$.

For the trials 1, 2 and 3, the von Mises stresses are, respectively, $168 \mathrm{MPa}, 168 \mathrm{MPa}$ and $168 \mathrm{MPa}$ (figure 10). For the trials 4, 5 and 6 , the von Mises stresses are, respectively, 163.8 $\mathrm{MPa}, 167.9 \mathrm{MPa}$ and 168 MPa. For the trials 7, 8 and 9, the von Mises stresses are, respectively, $168 \mathrm{MPa}, 160.7$ $\mathrm{MPa}$ and $168 \mathrm{MPa}$. The ultimate tensile strength of AA1050$\mathrm{H} 18$ alloy is $160 \mathrm{MPa}$ which is nearer for trials 3 and 5 .

\subsection{Influence of parameters on strain rate}

The ANOVA summary of the strain rate is given in Table 4. The percent contribution column establishes the major contributions $49.89 \%, 10.66 \%, 20.93 \%$ and $18.51 \%$ of sheet thickness, step depth, tool radius and coefficient of friction, respectively, towards variation in the strain rate.
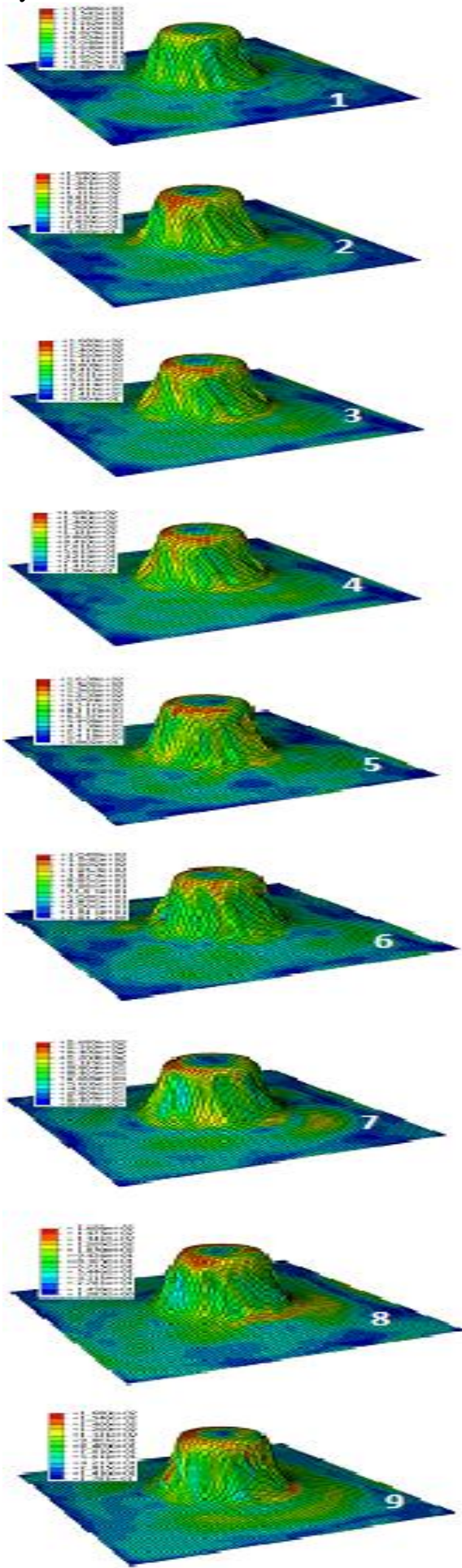

Figure 10: Raster images of von Mises stress in the cups.

Volume 5 Issue 6, June 2016 www.ijsr.net 


\section{International Journal of Science and Research (IJSR) \\ ISSN (Online): 2319-7064}

Index Copernicus Value (2013): 6.14 | Impact Factor (2015): 6.391

Table 4: ANOVA summary of the strain rate

\begin{tabular}{|c|c|c|c|c|c|c|c|c|}
\hline Source & Sum 1 & Sum 2 & Sum 3 & $S S$ & $v$ & $V$ & $F$ & $P$ \\
\hline A & 32.14 & 67.55 & 35.695 & 253.47 & 1 & 253.47 & 65441.17 & 49.89 \\
\hline B & 55.42 & 41.338 & 38.627 & 54.18 & 1 & 54.18 & 13988.25 & 10.66 \\
\hline C & 31.348 & 56.157 & 47.88 & 106.36 & 1 & 106.36 & 27460.14 & 20.93 \\
\hline D & 32.767 & 46.16 & 56.458 & 94.07 & 1 & 94.07 & 24287.1 & 18.51 \\
\hline E & & & & 0.015493 & 4 & 0.003873 & 1 & 0 \\
\hline T & $\begin{array}{c}151.67 \\
5\end{array}$ & 211.205 & 178.66 & 508.0955 & 8 & & & 100 \\
\hline
\end{tabular}
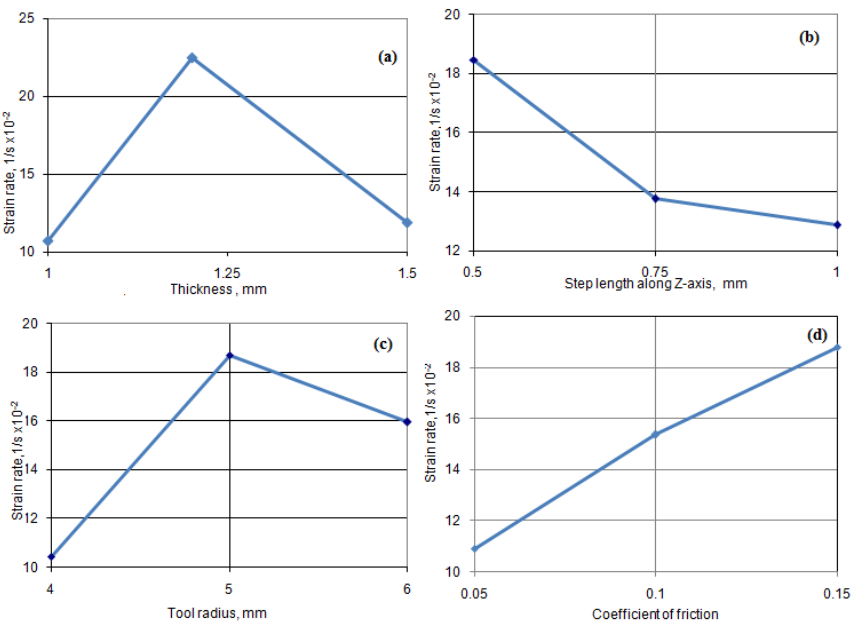

Figure 11: Influence of process parameters on strain rate.
The strain rate was found to be high for sheet thickness of $1.20 \mathrm{~mm}$ (figure 11a). As observed from figure 11b, the strain rate was decreased with increase of magnitude of the step $(\Delta \mathrm{z})$ downwards. For smaller step size local deformation plays an important role than stretching. While for larger step size, stretching dominates the local deformation. The strain rate was high for the tool radius of $5 \mathrm{~mm}$ ( figure 11c). The strain rate was proportional to coefficient of friction as shown in figure $11 \mathrm{~d}$. The frictional shear stress is a function of friction ( $\tau=\mu F_{n}$, where $F_{n}$ is the normal pressure).

\subsection{Influence of parameters on thickness reduction}

The ANOVA summary of the thickness reduction is given in Table 5. Tool radius, sheet thickness, step depth and coefficient of friction share in the decreasing order of their contribution $43.54 \%, 41.42 \%, 13.38 \%$ and $1.50 \%$ towards variation in the thickness reduction.

Table 5: ANOVA summary of the thickness reduction.

\begin{tabular}{|c|c|c|c|c|c|c|c|c|}
\hline Source & Sum 1 & Sum 2 & Sum 3 & $S S$ & $v$ & $V$ & $F$ & $P$ \\
\hline A & 259.71 & 256.272 & 251.00 & 12.83 & 1 & 12.83 & 1915.12 & 41.41 \\
\hline B & 257.91 & 256.100 & 252.97 & 4.15 & 1 & 4.15 & 619.46 & 13.38 \\
\hline C & 251.89 & 254.448 & 260.64 & 13.49 & 1 & 13.49 & 2013.64 & 43.54 \\
\hline D & 254.77 & 256.475 & 255.73 & 0.47 & 1 & 0.47 & 70.15 & 1.50 \\
\hline e & & & & 0.0279 & 4 & 0.0067 & 1 & 0 \\
\hline T & 1024.3 & 1023.29 & 1020.36 & 30.96 & 8 & & & 100 \\
\hline
\end{tabular}
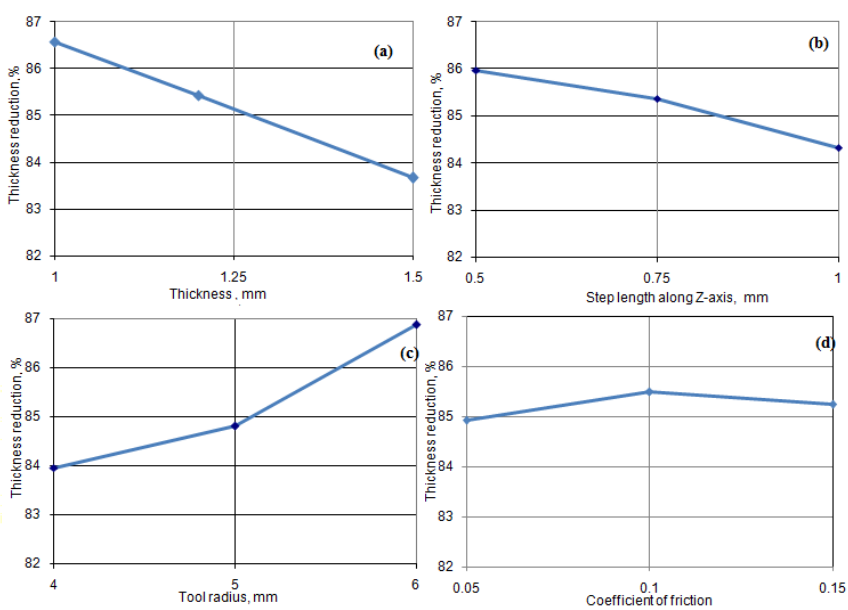

Step length along Z-axis, m

Figure 12: Influence of process parameters on thickness reduction

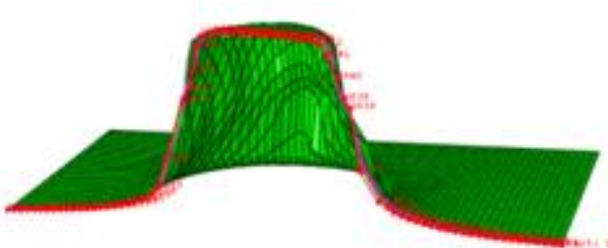

Figure 13: Location of thickness reduction in the deformed cup
The reduction of thickness was decreased with increase of sheet thickness as shown in figure 12a. This might be due to increase of resistance to plastic deformation in thick sheets for deep drawn of frustum of cone cups. The thickness reduction was decreased with increase of step depth (figure $12 \mathrm{~b})$. This might be due to small local plastic deformation with large step depth. The thickness reduction was increased with increase of tool radius (figure 12c). The coefficient of friction did not influence the thickness reduction ( figure $12 \mathrm{~d}$ ). The reduction of thickness was considered at the center-line of the deformed cup as shown in figure 13. As observed from figure 14, the majority of thickness reduction takes place in the upper part of the cup wall. Surprisingly, the sheet material in plastic state was pushed into lower of part cup wall wherein the thickness was built up. The elements located at the upper regions of the walls are elongated higher than those present at the lower regions of the cup walls. 


\section{International Journal of Science and Research (IJSR) \\ ISSN (Online): 2319-7064}

Index Copernicus Value (2013): 6.14 | Impact Factor (2015): 6.391
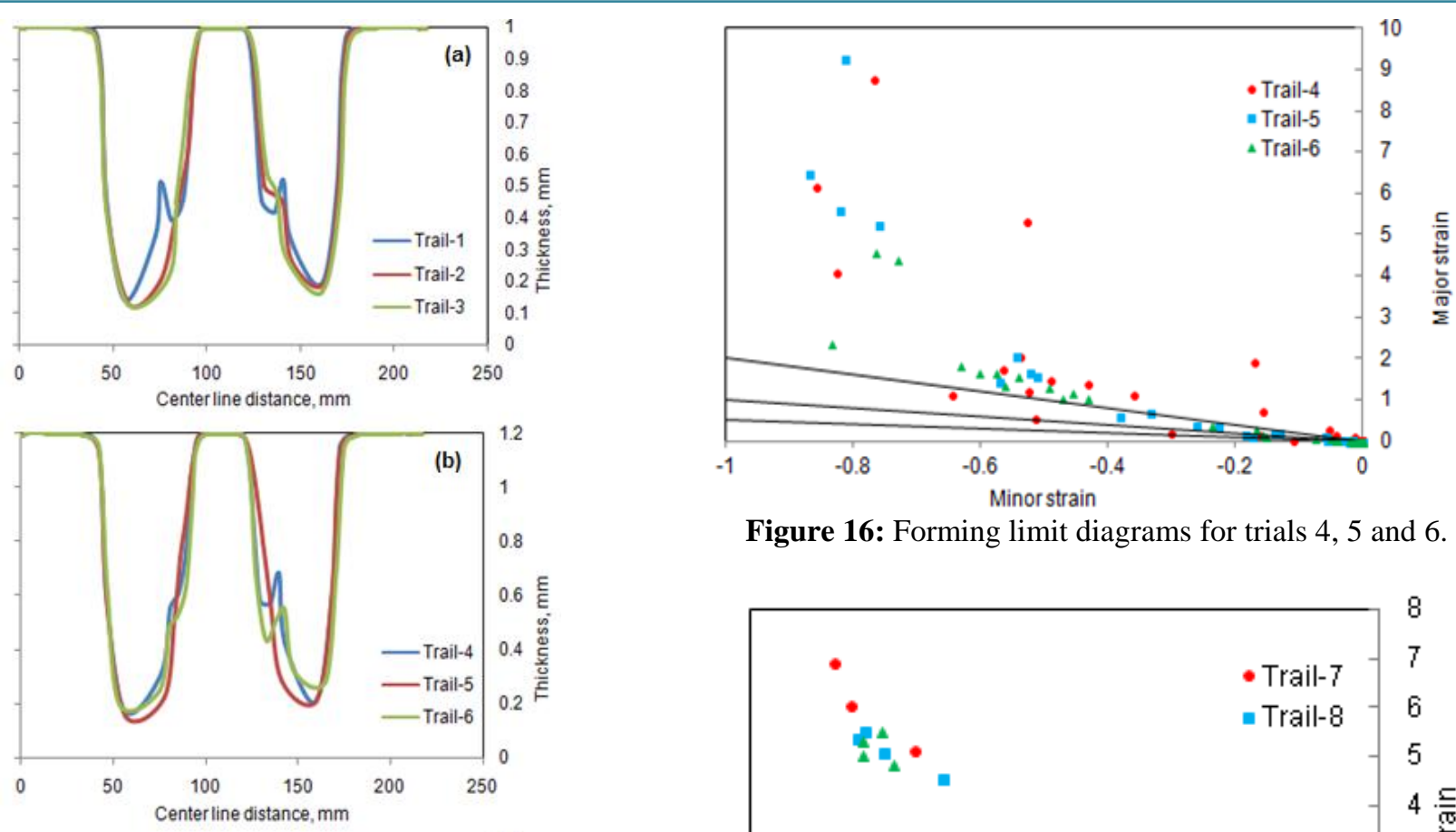

Figure 16: Forming limit diagrams for trials 4, 5 and 6.
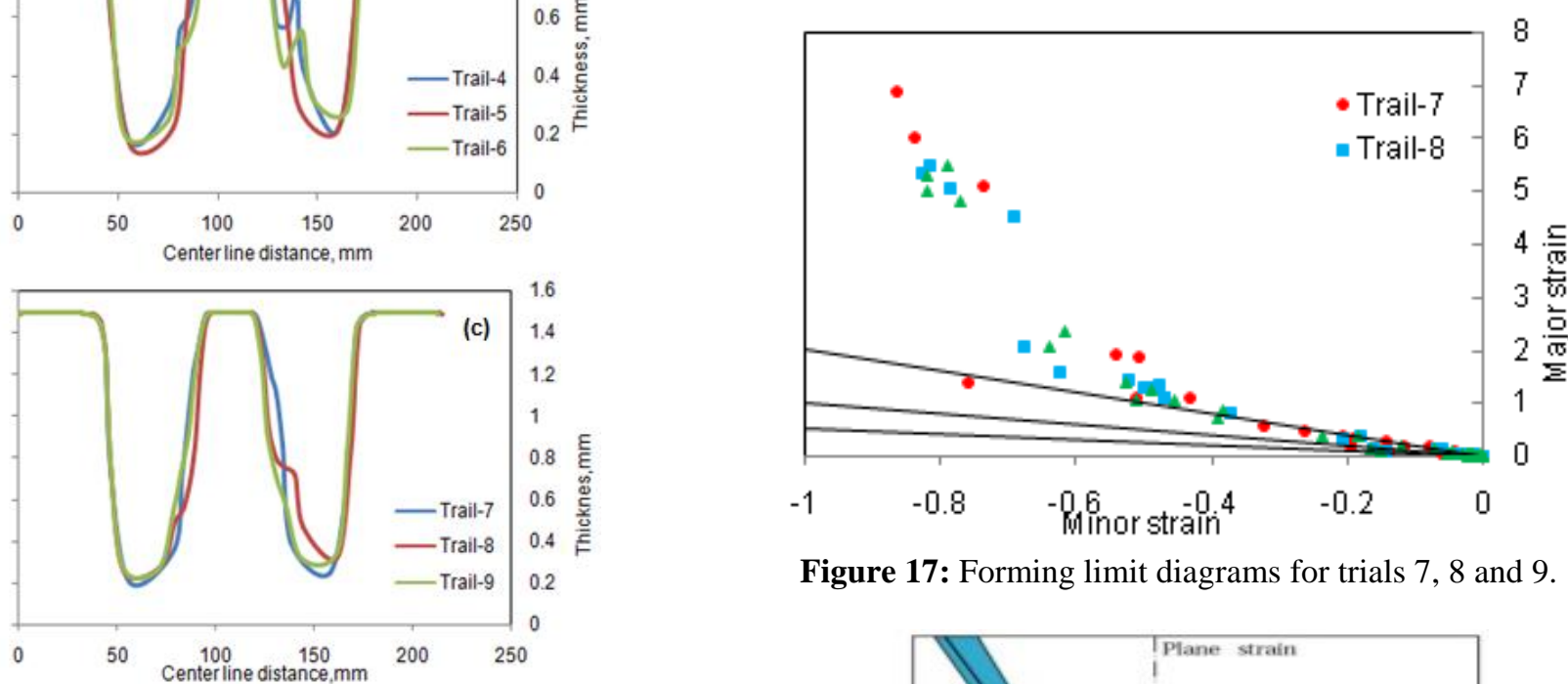

Figure 17: Forming limit diagrams for trials 7, 8 and 9.

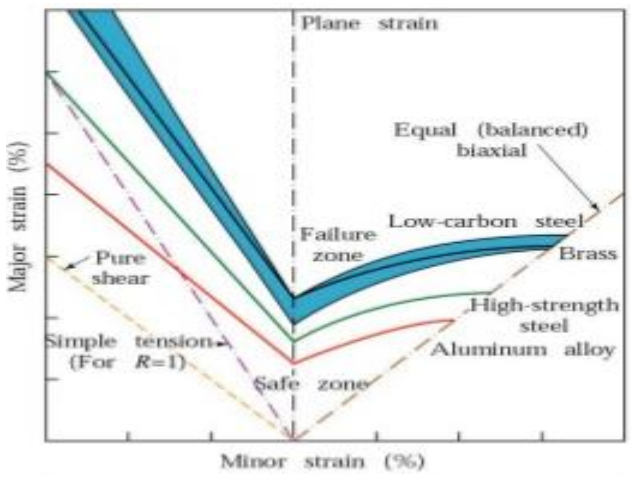

Figure 18: Forming limit diagram of deep drawing process ing the stretching sheet. For the trial 6 the formability limit diagram falls within the region of deep drawing process as compared with figure 18 . For the rest of trials, the formability limit diagrams fall within the region of failure due to simple tension.

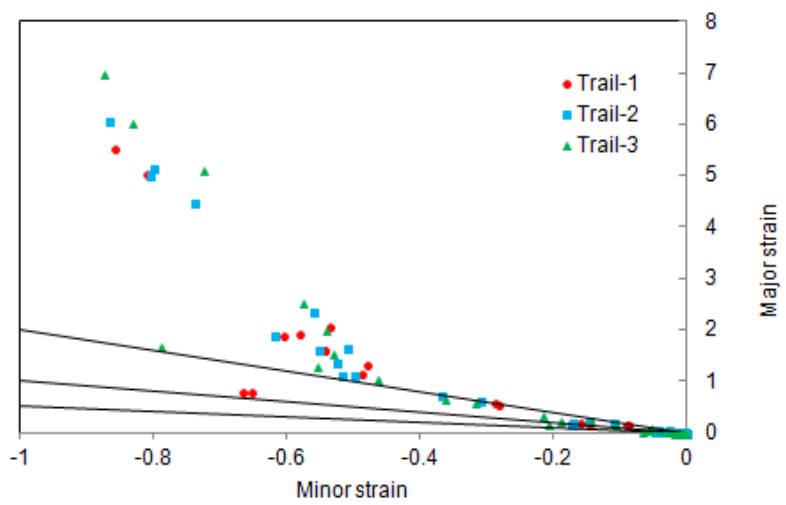

\section{Conclusions}

The major SPIF process parameters which influence the formability of frustum of cone cups of AA1050-H18 alloy were sheet thickness and tool radius. The optimal process parameters could be sheet thickness of $1.5 \mathrm{~mm}$, step depth of 0.5 $\mathrm{mm}$, tool radius of $4.0 \mathrm{~mm}$ and coefficient of friction of 0.05 .

\section{Acknowledgements}

The author acknowledges with thanks University Grants Commission (UGC) - New Delhi for sectioning R\&D project.

Figure 15: Forming limit diagrams for trials 1, 2 and 3.

Volume 5 Issue 6, June 2016 www.ijsr.net 


\section{International Journal of Science and Research (IJSR) \\ ISSN (Online): 2319-7064}

Index Copernicus Value (2013): 6.14 | Impact Factor (2015): 6.391

\section{References}

[1] A. C. Reddy, "Homogenization and Parametric Consequence of Warm Deep Drawing Process for 1050A Aluminum Alloy," Validation through FEA, International Journal of Science and Research, 4 (4), pp. 2034 2042, 2015.

[2] K. Chandini and A. C. Reddy, "Finite Element Analysis of Warm Deep Drawing Process for Pyramidal Cup of AA1070 Aluminum Alloy," International Journal of Advanced Research, 3(6), pp. 1325-1334, 2015.

[3] B. Yamuna and A. C. Reddy, "Finite Element Analysis of Warm Deep Drawing Process for Conical Cup of AA1080 Aluminum Alloy," International Journal of Advanced Research, 3(6), pp. 1309-1317, 2015.

[4] T. Srinivas and A. C. Reddy, "Finite Element Analysis of Warm Deep Drawing Process for Rectangular Cup of AA1100 Aluminum Alloy," International Journal of Advanced Research, 3(6), pp. 1383-1391, 2015.

[5] A. C. Reddy, "Parametric Optimization of Warm Deep Drawing Process of 2014T6 Aluminum Alloy Using FEA," International Journal of Scientific \& Engineering Research, 6(5), pp.1016-1024, 2015.

[6] A. C. Reddy, "Finite Element Analysis of Warm Deep Drawing Process for 2017T4 Aluminum Alloy: Parametric Significance Using Taguchi Technique," International Journal of Advanced Research, 3(5), pp. 12471255,2015

[7] A. C. Reddy, "Parametric Significance of Warm Drawing Process for 2024T4 Aluminum Alloy through FEA," International Journal of Science and Research, 4(5), pp. 2345-2351, 2015.

[8] A. C. Reddy, "Formability of High Temperature and High Strain Rate Superplastic Deep Drawing Process for AA2219 Cylindrical Cups," International Journal of Advanced Research, 3(10), pp. 1016-1024, 2015.

[9] A. C. Reddy, "High temperature and high strain rate superplastic deep drawing process for AA2618 alloy cylindrical cups," International Journal of Scientific Engineering and Applied Science, 2(2), pp. 35-41, 2016.

[10]A. C. Reddy, "Practicability of High Temperature and High Strain Rate Superplastic Deep Drawing Process for AA3003 Alloy Cylindrical Cups," International Journal of Engineering Inventions, 5(3), pp. 16-23, 2016.

[11] A. C. Reddy, "Suitability of High Temperature and High Strain Rate Superplastic Deep Drawing Process for AA5052 Alloy," International Journal of Engineering and Advanced Research Technology, 2(3), pp. 11-14, 2016.

[12] A. C. Reddy, "High temperature and high strain rate superplastic deep drawing process for AA5049 alloy cylindrical cups," International Journal of Engineering Sciences \& Research Technology, 5(2), pp. 261-268, 2016.

[13] A.C. Reddy, "Finite element analysis of reverse superplastic blow forming of Ti-Al-4V alloy for optimized control of thickness variation using ABAQUS," Journal of Manufacturing Engineering, 1(1), pp.6-9, 2006.

[14] A. C. Reddy, T. K. K. Reddy, M.Vidya Sagar, "Experimental characterization of warm deep drawing process for EDD steel," International Journal of Multidisciplinary Research \& Advances in Engineering, 4(3), pp.5362, 2012.
[15] A. C .Reddy, "Evaluation of local thinning during cup drawing of gas cylinder steel using isotropic criteria," International Journal of Engineering and Materials Sciences, 5(2), pp.71-76, 2012.

[16]A. C. Reddy, "Formability of Warm Deep Drawing Process for AA1050-H18 Pyramidal Cups," International Journal of Science and Research, 4(7), pp. 2111-2119, 2015.

[17]A. C. Reddy, "Formability of Warm Deep Drawing Process for AA1050-H18 Rectangular Cups," International Journal of Mechanical and Production Engineering Research and Development, 5(4), pp. 85-97, 2015.

[18] A. C. Reddy, "Formability of superplastic deep drawing process with moving blank holder for AA1050-H18 conical cups," International Journal of Research in Engineering and Technology, 4(8), pp. 124-132, 2015.

[19] G. Hussain, L. Gao, Z. Y. Zhang , "Formability evaluation of a pure titanium sheet in the cold incremental forming process," International Journal of Advanced Manufacturing Technology, 37, pp.920-266, 2008.

[20]F. C. Minutolo, M. Durante, A. Formisano, A. Langella,. "Evaluation of the maximum slope angle of simple geometries carried out by incremental forming process," Journal of Materials Process Technology, 194, pp. 145-150, 2007.

[21] Chennakesava R. Alavala, "Finite element methods: Basic Concepts and Applications, PHI Learning Pvt. Ltd., 2008.

[22] Chennakesava, R. Alavala, "CAD/CAM: Concepts and Applications,” PHI Learning Pvt. Ltd, 2008. 